Wilkening, Gene

1978 "Wisconsin Farmer Survey." Madison: Department of Ruteal Sociology, University of Wisconsin.

Zald, Mayer N. and Roberta Ash

1966 "Social Movement Organizations: Growth, Decay, and Change". Social Forces Vol 44, No. 3 (March):327-41

Zald, Mayer N. and John D. McCarthy

1972 "America and the Rise of Social Movements." New Society Vol. 20, No. 509 (June):670-2.

\section{HEALTH SELF-REPORT CORRELATES AMONG OLDER PEOPLE IN NATIONAL RANDOM SAMPLE DATA}

Marshall J. Graney

Wayne State University

\section{Renee M. Zimmerman}

University of Kansas

Mid-American Review of Sociology, 1980, Vol. V, No, 2:47-59

Older people's health self-reports (HSRs) are frequently cited in explanations for changes in social status (e.g., retirement), social participation-activity (e.g., disengagement), and personal attitudes (e.g., life satisfaction). The purpose of research reported here was to establish correlates of HSRs in U.S. national random sample data. The parametric analysis strategy was applied to data on all persons aged $65+$ interviewed for the Harris-NCOA survey $(N=$ 2797), with results as follows: social status (2 variables, largest $\left.r^{2}<0.15\right)$, social participation-activity $(5$ variables, largest $\left.r^{2}<0.25\right)$, and personal attitudes $\left(10\right.$ variables, largest $r^{2}<$ $0.15)$. Ail variables analyzed were correlated to HSR at the 0.001 level or beyond. These results confirm findings from studies using smaller or specialized samples, and they present new evidence of the importance of social participation-activity to the HSRs of older people.

\section{INTRODUCTION}

Purpose and Scope

The importance of health in the lives of older people is shown by the fact that personal health is one of the most frequent explanations they offer for changes in social status (e.g., retirement), social participation-activity (e.g., disengagement), and personal attitudes (e.g., life satisfaction). Research has shown that the attitudes and behaviors of older people are more closely related to their health self-reports (HSRs) than to physiologicalmedical evaluations of health by others (Friedsam and Martin, 1963; Maddox and Douglass, 1973), which demonstrates the importance in HSRs. 
Past research has found linkages between HSRs and physio. logical-medical health, social status attributes, social participation. activity, and personal attitudes. Without exception these findings have been based on data from samples that were either small in size, or specialized, or geographically restricted, or some com bination of these limitations on generalizability has prevailed Nevertheless, these findings are potentially verifiable, and the chief purpose of this study was to establish correlates of HSR in data from a large-scale contemporary U.S. national random sample of people aged 65 years old and over.

\section{HSR RESEARCH}

\section{Hypotheses}

In general agreement with Friedsam and Martin (1963) Maddox (1962) and Suchman et al. (1958), we have classified variables that could be considered as potential HSR correlates into four categories: 1) social status attributes, 2) social par ticipation-activity measures, 3) personal attitudes, and 4) physio logical-medical health evaluations. The relationship between HSRs and physiological-medical health evaluations is reviewed below under the heading Health Measurement, and the relationships between HSRs and variables in the other three categories are examined in this study through three research hypotheses:

Hypothesis I: Advantageous social status attributes are directly correlated to HSRs.

Hypothesis II: Social participation-activity measures are directly correlated to HSRs.

Hypothesis III: Positive personal attitudes are directly correlated to HSRs.
Health Measurement ${ }^{1}$

Several kinds of questions have been used to measure health in survey research, including checklists of health problems, medicines taken, and illness or disabilities. Data on these three variables have been found to correlate to $\mathrm{r}=0.58,0.52$ and 0.54 (all $\mathrm{p}<0.001$ ) with a four point overall self-evaluation of health (Fillenbaum, 1979). Haberman (1969) has found that correlations between HSR measures and physiological-medical health evaluations by others are rarely perfect, but pairs of HSR and physiological-medical health evaluations are "predominantly congruent" in the sense that these measures are found to be in agreement more often than in disagreement (Maddox and Douglass, 1973). However, more than a third of such pairs have been found to be in disagreement (Friedsam and Martin, 1963; 39 percent; Maddox and Douglass, 1973: 36 percent; Suchman et al., 1958: 37 percent). It appears that people in general either overrate their health, or that older people tend to adjust their health expectations downward relative to physiological-medical standards, because three-fifths or more of the disagreements represent HSRs more favorable than physiological-medical evaluations (Friedsam and Martin, 1963: 79 percent; Maddox and Douglass, 1973: 67 percent; Suchman et al., 1958: 60 percent).

Because one kind of disagreement (the optimistic HSR) is more common than the other (the pessimistic HSR), the correlation between HSR and physiological-medical health assessment has been found to be less than the maximum value that it could otherwise attain (assuming 33 percent disagreement and a pair of dichotomous variables of maximum $r$ of 0.44 could be obtaired; corresponding to a coefficient of determination showing almost 20 percent shared variance). Thus, correlations of $r=0.24$ (Friedsam and Martin, 1963), 0.26 (Maddox and Douglass, 1973), and 0.17 (Suchman et al., 1958) have been attained. Although these correlation coefficients are statistically significant at the 0.01 level or beyond, the corresponding coefficients of determination demonstrate only six, seven, and three percent shared variance because of information loss inherent in the dichotomization of polytomous variables. The importance of preserving information 
in HSR data analysis is evident in the findings of Palmore and Luikart (1972), who demonstrate more than eighteen percent shared variance between the two variables $(r=0.43, p<0.001)$

These findings show that HSRs obtained in survey research are in general agreement with clinical health assessments. However, a substantial proportion of older people rate their state of health as favorable despite facts of illness or reduced vigor that might provide bases for unfavorable reports, and a small proportion of older people make unfavorable HSR evaluations even though physiological-medical evidence is not unfavorable.

\section{HSR and Social Status Attributes}

Social status attributes or "social placement factors" have been found to be correlates of HSRs (Maddox, 1962). Extent of formal education, in particular, has been noted as a surrogate for a number of different concepts, including intelligence, nutrition. health care, and the general advantages of upper socio-economic status, by Palmore and Luikart (1972) who found that educational attainment explained four percent of HSR variance. To assess the strength of the HSR-education correlation we have included a measure of educational attainment in the analysis.

Another social status variable included in our analysis of HSR correlates is the older person's perceptions of financial inadequacy. This financial self-perception, like education, can be considered to be a member of the class of socioeconomic status (SES) measures discussed by Palmore and Luikart (1972).

\section{HSR end Social Participation-Activity}

Social participation-activity measures have been linked to HSRs in previous research. For example, Palmore and Luikart (1972) analyzed correlations between HSR and both genera activity and sexual enjoyment, but less than two percent shared variance was demonstrated by either of the coefficients of deter mination. Other research has been consistent in demonstrating statistical significance for associations, and although insufficient information is available to permit estimation of shared variance in these studies the explained variance does not appear to be substantially larger than that found by Palmore and Luikart (Friedsam and Martin, 1963; Suchman et al., 1958).

Research to be reviewed below reports important linkages between HSR and life satisfaction, and linkages between social participation-activity and life satisfaction among older people have been reviewed and demonstrated elsewhere (cf. Graney, 1975). Because of the importance of these linkages we believe that previous research findings of HSR associations with social participation-activity underestimate the substantive significance of social participation-activity to HSR. For this reason the conceptual interest area of social participation-activity has been operationalized as five separate variables for data analysis: 1) activity in general, 2) sexual activity in particular, 3) hobbies, and 4) clubs and voluntary organizations, and 5) interaction with friends.

\section{HSR and Personal Attitudes}

Several contributions to research on older people's HSRs have highlighted correlations with personal attitudes reflecting life satisfaction. Maddox's (1962) research established the correlation and found that a positive condition of self-rated health is one of the most frequently-cited explanations offered for attitudes reflecting life satisfaction among older people. Further, Palmore and Luikart (1972) have observed that HSR is the variable most related to life satisfaction in their data.

Maddox (1962) and Maddox and Douglass (1973) have found the correlation between HSR and attitudes to be larger than that between physiological-medical measures and attitudes, and Suchman et al. (1958), concluded from their data that "... selfratings of health are more closely related to the attitudinal items under consideration than physician's ratings." Similar results have been obtained by Friedsam and Martin (1963), and by Tissue (1973) a decade later. Data on ten measures of personal attitudes are included in the analysis below. 
METHOD

Sample

Our analysis is based on survey data collected for the $\mathrm{Na}$ tional Council on Aging by Louis Harris and Associates. This survey was a multi-stage random cluster sample of households in the continental United States using sampling procedures that have been described in detail elsewhere (Harris, 1975). A total of 4,254 persons were interviewed, of whom 2,797 were sixty five years old or older. The analysis reported here is based on data from these 2,797 older people, whose major demographic characteristics have been published elsewhere (Harris, 1975).

Variables $^{2}$

Data on eighteen variables were analyzed for this report. The dependent variable was HSR, operationalized in the survey question "How serious a problem would you say poor health is to you personally these days?"3 The variable names, and the questions on which they were based, for the independent variables are organized below according to the research hypothesis they were used to test.

Hypothesis I; Social Status Attributes. ${ }^{4}$ The first of two social status variables analyzed was Education: "What was the highest grade of school that you actually completed?" The other social status variable was Financial Inadequacy: "How serious a problem would you say not having enough money to live on is for you personally these days?"

Hypothesis II; Social Participation-Activity. ${ }^{5}$ General Activity: "Would you say you are very physically active?" Sexual Activity: "Would you say you are sexually active?" Hobbies: "How much time do you personally spend in recreational activities and hobbies?" Organization: "How much time do you per sonally spend participating in fraternal or community organiza? tions or clubs?" Friends: "How much time do you personally spend socializing with friends?"
Hypothesis III; Personal Attitudes. ${ }^{6}$ Alert: "Would you say you are very bright and alert?" Ability: "Would you say you are good at getting things done?" Optimism: "As I grow older things seem better than I thought they would be." Satisfaction: "These are the best years of my life." Useful: "Do you feel that you personally are a very useful member of your community at all?" Sedentary: "How much time do you personally spend at sitting and thinking?" Unhappiness: "My life could be happier than it is now." Lonely: "How serious a problem would you say loneliness is for you personally these days?" Unneeded: "How serious a problem would you say not feeling needed is for you personally these days?" Feeling Old: "I feel old and somewhat tired."

\section{RESULTS $^{7}$}

The hypothesis that differences in social status attributes are related to differences in HSR (Hypothesis I) was studied using two variables, including 1) the respondent's self-report regarding attainment of formal education, and 2) self-reported financial inadequacy, which can be anticipated to be inversely related to HSR. Both correlations were in the predicted directions, and the correlations to education and to perceived financial inadequacy were statistically significant at the 0.001 level or beyond, as shown in Table 1. Partial correlation coefficients tabulated in Table 1 demonstrate the importance of the perception of a status of financial inadequacy to HSR, because when all other correlates of HSR, analyzed in this study, were controlled for this coefficient was -0.27 .

When only the bivariate relationship between financial in adequacy and HSR is considered we find that more than eighteen percent of variance in HSR is explained by the financial inadequacy variable.

The hypothesis that differences in social participation-activity are related to differences in HSR, Hypothesis II, was studied using five activity self-reports. These variables included measures of general activity, sexual activity, hobbies, organizational participation, and interaction with friends. All five correlations were in the predicted direction, and all correlation coefficients were 
TABLE 1

Self-Report with Selected Variables ${ }^{a}$

\begin{tabular}{|c|c|c|c|c|}
\hline an: & Variable & $\mathbf{r}$ & $r^{2}$ & Partial $\mathbf{r}^{\mathbf{b}}$ \\
\hline
\end{tabular}

\section{Social Status}

\section{Education}

Financial Inadequacy

$0.26 * * * \quad 0.07 * * *$

$-0.42 * * * \quad 0.18 * * *$

$0.10^{*}$

Social Participation-Activity

General Activity

Sexual Activity

Hobbies

Organizations

Friends

Personal Attitudes

$\begin{array}{lccc}\text { Alert } & 0.26 * * * & 0.07^{* * *} & -0.09 \\ \text { Ability } & 0.36^{* * *} & 0.13^{* * *} & 0.05 \\ \text { Optimistic } & 0.24 * * * & 0.06^{* * *} & -0.05 \\ \text { Satisfied } & 0.26 * * * & 0.07 * * * & 0.05 \\ \text { Useful } & 0.26 * * * & 0.07^{* * *} & 0.02 \\ \text { Sedentary } & -0.26 * * * & 0.07^{* * *} & -0.07 \\ \text { Unhappy } & -0.28^{* * *} & 0.08^{* * *} & -0.03 \\ \text { Unneeded } & -0.29 * * * & 0.08^{* * *} & -0.01 \\ \text { Feeling Old } & -0.38 * * * & 0.14^{* * *} & -0.15^{* *} \\ \text { Lonely } & -0.41 * * * & 0.17^{* * *} & -0.15^{* *}\end{array}$

a Based on cases for which complete data are available.

$b$ Adjusted for all other independent variables analyzed.

$*_{p}<0.05$.

$* * \mathrm{p}<0.01$.

$* * * \mathrm{p}<0.001$ statistically significant at the 0.001 level or beyond, with values as shown in Table 1. The general activity self-report was the most valuable single predictor of HSR found in this study, with more than twenty-eight percent of HSR variance shared with the general activity variable in their bivariate relationship. Computation of the general activity-HSR partial correlation coefficient yielded a value of 0.31 , which can be interpreted as an indication that the general activity measure should not be considered to have excessive multicollinearity with the other correlates of HSR variations examined in this study under the social status, social participationactivity, or personal attitudes headings.

The hypothesis that differences in personal attitudes are related to differences in HSR, hypothesis III, was studied using ten self-ratings of attitudinal variables. Five of these variables were measures of feelings, generally considered to be positive, including: self-ratings of alertness, ability, optimism, satisfaction, and feeling useful; and five were measures of feelings generally considered to be negative, including: being sedentary, unhappiness, loneliness, feeling unneeded, and feeling old. All ten correlations were in the predicted directors, and all ten correlations coefficients were statistically significant at the 0.001 level or beyond. The most important attitudinal variables for explaining variance in HSR were feelings of loneliness and feeling old, whose bivariate relationships with HSR each shared more than ten percent of HSR variance. Further analysis using partial correlation coefficients shows that there is considerable noncollinearity between these two attitudinal measures and the other correlates of HSR included in this study, according to findings tabulated in Table 1.

\section{DISCUSSION}

Research findings presented in this study confirm and demonstrate generalizability of past research. In addition, the findings include new evidence of the importance of social participationactivity to HSR and reassert the importance of social status factors and personal attitudes. 
Selected measures of social status, social participationactivity, and personal attitudes have all been found to be signiff. cantly related to HSRs, and consideration of coefficients of de: termination shows that at least one variable in each of these three major conceptual areas shares an amount of variance with HSR that is approximately equal to or exceeds the relatively large amount of shared variance found in previous research relating HSRs and physiological-medical health assessments of older people. This research evidence demonstrates that sociological variables (e.g., social status measures and social participation activity measures) as well as social-psychological variables (e.g. measures of personal attitudes) may be as important to an older person's health self-conception as those kinds of physiological medical factors generally considered by physicians in develop. ing their health evaluation of older people. In terms of relative importance among various measures of social status, social par ticipation-activity, and personal attitudes, the largest single correlation to HSR observed in this study was a positive correlation with a social participation-activity measure of general activity, followed by an inverse correlation with a social status measure of financial inadequacy. The largest social status measure co. efficient of determination showing eighteen percent shared variance. All five measures of social participation-activity shared at least five percent variance with HSR, and the largest social participation-activity coefficient of determination (General Activity) showed twenty-eight percent shared variance. All ten measures of personal attitudes shared at least seven percent of variance with HSR, and the largest personal attitude measure coefficient of determination (Lonely) showed seventeen percent shared variance.

Analysis of partial correlation coefficients shows that there are substantial amounts of intercorrelation among the eighteen independent variables considered in this study. However, within each of the three sets of variables used as measures of social status, social participation-activity, or personal attitudes, there was found to be at least one variable whose partial correlation to HSR demonstrated considerable importance even when the effects of all the other independent variables was controlled for in analysis. Among measures of social status the most salient variable was the older person's report regarding financial inadequacy, with a partial r of -0.27 ; among measures of social participation-activity the most salient variable was general activity, with a partial $r$ of 0.31 ; and among measures of personal attitudes both "feeling old" and "feeling lonely" has partial r's of -0.15 .

Findings presented in this report on social status and personal attitudes, in particular, confirm and strengthen confidence in findings from past research because both social status and personal attitudes have now been shown to be as highly correlated with HSR in national random sample data as they were in data obtained from small or specialized samples. A new finding presented in this research report is the increased importance of social participation-activity measures over that estimated in previous research. Our analysis shows social participation-activity to be as highly correlated to HSR, or more highly correlated, than physician's health assessments have been found in past research.

\section{SUMMARY}

Data on 2,797 persons aged 65 and over was collected on a U.S. national random sample by the NCOA-Harris survey and analyzed in a study of health self-report correlates among older people. Three categories of correlates have been established in past research, including social status attributes, social participation-activity, and personal attitudes, and these findings were confirmed. It was proposed that social participation-activity bears much greater substantive importance to HSR than previous research has shown (findings show more than twenty-five percent shared variance between HSR and general activity).

In sum, the correlates of HSR found in research using small or specialized samples have been confirmed in analysis of U.S. national random sample data, and new emphasis has been placed on social participation-activity as a result of these findings. 


\section{FOOTNOTES}

1. Some of the statistics presented here have been computed to enhanc comparability of findings between studies.

2. The language of the interview questions' fixed-alternative response categories and scoring/codes has been previously published (Campbell et al., 1974) and is not reproduced here. Scoring has been reversed for HSR response categories for internal consistency and to aid compatability of findings to other studies of HSR.

3. In Campbell et al. (1974), this variable is designated SNOHEL.

4. In Campbell et al. (1974), these variables are designated EDUC, and SNOMON.

5. In Campbell et al. (1974), these variables are designated SACTIV, SSEX. SHOBBY, SCLUB, and SFRND.

6. In Campbell et al. (1974), these variables are designated SALERT, SHANDY, BETTER, BESTYRS, SUSEFL, STHINK, HAPPIER, SLONE SNONED, and FEELOLD.

7. The parametric strategy (Kim, 1974) utilizing integer transformations of ordinal code values from Campbell et al. (where applicable) has been used in preparing data for analysis.

\section{REFERENCES}

Campbell, Richard T., Gloria Gardocki, John C. Henretta, and Kristin Paulig 1974 Codebook for "The Myth and Reality of Aging." Durham, Norti Carolina: Duke University Medical Center.

Friedsam, H.J., and H.M. Martin

1963 " $\mathrm{A}$ comparison of self and physicians' health ratings in an oldet population." Journal of Health and Social Behavior 4:179-83

Fillenbaum, G.G.

1979 "Social context and self-assessment of health among the elderly." Journal of Health and Social Behavior 20:45-51.

\section{Graney, M.J.}

1975 "Happiness and social participation in old age." Journal of Geron tology 30:701-6.
Haberman, $P$.

1969 "The reliability of data." Pp. 343-83 in John Kosa, Aaron Antonovsky, and Irving K. Zola (eds.), Poverty and Health. Cambridge, Mass.: Harvard University Press.

Harris, Louis, and Associates

1975 The Myth and Reality of Aging. Durham, North Carolina: Duke University Press.

Kim, J.

1974 "The multivariate analysis of ordinal gata." American Journal of Sociology $81: 261-98$.

LaRue, A., L. Bank, L. Jarvik, and M Hetland

1979 "Health in old age: How do physician's ratings and self-ratings compare?" Journal of Gerontology 34:687-91.

Maddox, G.L.

1962 "Some correlates of differences in self-assessment of health status among the elderly." Journal of Gerontology 17:180-5.

Maddox, G.L. and E.B. Douglass

1973 "Self-assessment of health: A longitudinal study of elderly subjects." Journal of Health and Social Behavior 14:87-93.

Palmore, E. and C. Luikart

1972 Health and social factors related to life satisfaction. Journal of Health and Social Behavior 13:68-80.

Suchman, E.G., B.S. Phillips, and G.F. Streib

1958 "An analysis of the validity of health questionnaires." Social Forces 36:223-32

Tissue, $\mathrm{T}$.

1972 "Another look at self-rated health among the elderly." Journal of Gerontology $27: 914$ 